\title{
The head anatomy of Epiophlebia superstes (Odonata: Epiophlebiidae)
}

\author{
Alexander Blanke • Felix Beckmann • Bernhard Misof
}

Received: 16 February 2012 / Accepted: 1 June 2012

(C) Gesellschaft für Biologische Systematik 2012

\begin{abstract}
The relic dragonfly family Epiophlebiidae is recovered as sistergroup of Anisoptera (= Epiprocta) by most molecular and morphological analyses. However, in a recent study it was placed within Anisoptera as sister group of Cordulegastridae. In another study, several affinities to Zygoptera in the morphology of the ovipositor and the egg-laying behaviour were pointed out. Here, we present a detailed study of the outer, as well as the inner, head morphology of Epiophlebia superstes. Compared with the last detailed literature account, three additional mandibular muscles were discovered, as well as additional buccal and pharyngeal muscles. The results are compared with the anatomic features of Zygoptera and Anisoptera. A formal character evaluation focused on head characters confirms the sistergroup relationship of Epiophlebiidae and Anisoptera.
\end{abstract}

Keywords Muscle equipment · Zygoptera · Anisoptera . Anisozygoptera · Epiophlebiidae · Phylogeny · Anatomy · MicroCT $\cdot 3 \mathrm{D}$-reconstruction $\cdot$ Epiprocta

Electronic supplementary material The online version of this article (doi:10.1007/s13127-012-0097-z) contains supplementary material, which is available to authorized users.

\footnotetext{
A. Blanke $(\square) \cdot$ B. Misof

Zentrum für molekulare Biodiversität, Zoologisches

Forschungsmuseum Alexander Koenig,

Adenauerallee 160,

53113, Bonn, Germany

e-mail: blanke@uni-bonn.de

F. Beckmann

Institute of Materials Research, Helmholtz-Zentrum Geesthacht,

Max-Planck-Str. 1,

21502, Geesthacht, Germany
}

\section{Introduction}

The dragonfly Epiophlebia superstes is one of three species of the relict family Epiophlebiidae (Odonata: Anisozygoptera). These species are restricted to the oriental region, with E. superstes occurring only in Japan and Epiophlebia laidlawi found only in the Himalaya region (Tillyard 1921). The third species-Epiophlebia siniensis - was discovered very recently in China in a habitat similar to that of the other two species (Li et al. 2012).

Molecular, as well as morphological, studies consistently retrieve Epiophlebiidae as a sistergroup of Anisoptera (Bechly 1996; Bybee et al. 2008; Carle 1982; Gade et al. 2011; Lohmann 1996; Misof et al. 2001; Rehn 2003; Trueman 1996) with the exception of Dumont et al. (2010) who recovered Epiophlebiidae as the sistertaxon to Cordulegastridae (Anisoptera) based on $18 \mathrm{~S}, 5.8 \mathrm{~S}$, and ITS1 and 2 sequences.

Owing to its assumed phylogenetic position, representatives of this family are crucial in comparative studies. Epiophlebiidae exhibit zygopteran, as well as anisopteran, features; for example, in Zygoptera the wings are held back over the abdomen at rest, the proventriculus is 16-folded and transverse muscles in the rectal gills are absent. Anisopteran features are the shape of the abdominal tergites, the broader hind wing than the forewing and the morphology of the larva (except the pronymph) (see Asahina 1954: 119 for a complete overview).

Owing to its specific phylogenetic position the morphology of $E$. superstes has been investigated intensively ( Ando 1962; Asahina 1954) by dissection and subsequent light microscopy. A recent detailed account of the ovipositor of E. superstes using the same methods revealed several affinities with Zygoptera, particularly concerning internal features and egg-laying behaviour (Matushkina 2008). The author also found additional muscles and characteristic 
muscle branches compared with those described in the earlier study of Asahina (1954).

Despite these intensive investigations several morphological features remain not yet adequately described. This is especially true for the inner anatomy, for example the muscle equipment of the head and head appendages.

Thus, the aim of the present study is to provide a detailed description of head morphology with a special focus on the musculature. The characters will be evaluated with respect to their implications for the phylogenetic placement of Epiophlebiidae within Odonata.

\section{Materials and methods}

We used two freshly collected specimens of E. superstes and several species of Zygoptera and Anisoptera for comparison (Table 1), which were all fixed in Bouin solution (Romeis 1989) for several days. Afterwards, specimens were washed several times in $70 \% \mathrm{EthOH}$ and stored in $80 \%$ EthOH.

Table 1 Scanning parameters used for the investigated taxa; for the scans at Deutsches Elektronen-Synchotron (DESY; Hamburg, Germany) and PSI (Villigen, Switzerland) monochromatic X-rays are

\section{Computer tomography}

The anatomy was investigated using synchrotron microComputer Tomography (SR-microCT) (Betz et al. 2007). Prior to scanning, the sample was critical point dried (CPD) (Model E4850, BioRad, Hercules, CA, USA) to avoid shrinking artefacts and mounted on specimen holders. Scanning was performed at beamline BW2/DORIS III at the Deutsches Elektronen-Synchrotron (DESY) (Hamburg, Germany) and with TOMCAT beamline using a monochromatic X-ray beam at the Paul Scherrer institute (PSI) (Villigen, Switzerland). The tomography station operated by Helmholtz-Zentrum Geesthacht (HZG) (Geesthacht, Germany) at DORIS III is optimized for performing highdensity resolution microtomography (Beckmann et al. 2008). Additional specimens were scanned at the high resolution computed tomography scanner, $\mathrm{v} \mid$ tome|x s (GE phoenix|x-ray, Steinmann-Institut, Bonn, Germany). Subsequent segmentation and rendering was accomplished with Reconstruct (Fiala 2005) and Blender (blender.org). Both software packages are distributed under the general public

used. Epiophlebia superstes was scanned twice as the first scan was not sufficient to display the anatomical details required

\begin{tabular}{|c|c|c|c|c|c|}
\hline \multirow[t]{2}{*}{ Family } & \multirow[t]{2}{*}{ Species } & \multirow[t]{2}{*}{ Facility } & \multicolumn{3}{|c|}{ microCT specifications } \\
\hline & & & Energy $[\mathrm{keV}]$ & Magnification & Pixel size $(\mu \mathrm{m})$ \\
\hline Coenagrionidae & Coenagrion puella & SLS & 10 & 4 & 1.85 \\
\hline Coenagrionidae & Pyrrosoma nymphula & SLS & 10 & 4 & 1.85 \\
\hline Platycnemididae & Platycnemis pennipes & SLS & 10 & 4 & 1.85 \\
\hline Platycnemididae & Platycnemis latipes & SLS & 10 & 4 & 1.85 \\
\hline Calopterygidae & Calopteryx virgo & DESY & 8 & 3.4 & 4.96 \\
\hline Lestidae & Lestes virens & DESY & 8 & 3.4 & 4.96 \\
\hline \multirow[t]{2}{*}{ Epiophlebiidae } & \multirow[t]{2}{*}{ Ephiophlebia superstes } & DESY & 8 & 1.9 & 9.46 \\
\hline & & SLS & 10 & 2 & 3.7 \\
\hline Neopetaliidae & Neopetalia punctata & SLS & 10 & 2 & 3.7 \\
\hline Gomphidae & Onychogomphus forcipatus & DESY & 8 & 1.9 & 9.46 \\
\hline Gomphidae & Gomphus pulchellus & DESY & 8 & 2.7 & 5.01 \\
\hline Austropetaliidae & Phyllopetalia apicalis & SLS & 10 & 2 & 3.7 \\
\hline Aeshnidae & Aeshna mixta & DESY & 8 & 3.7 & 3.73 \\
\hline Aeshnidae & Anax imperator & SI & 20.5 & 4 & 7.87 \\
\hline Cordulegastridae & Cordulegaster bidentata & SI & 20.5 & 4 & 7.87 \\
\hline Petaluridae & Uropetala chiltoni & SI & 20.5 & 4 & 7.87 \\
\hline Macromiidae & Macromia taeniolata & SLS & 10 & 2 & 3.7 \\
\hline Corduliidae & Cordulia aenea & SI & 20.5 & 4 & 7.87 \\
\hline Libellulidae & Sympetrum sanguineum & DESY & 8 & 2.7 & 5.01 \\
\hline Libellulidae & Libellula depressa & DESY & 8 & 3.7 & 4.13 \\
\hline Libellulidae & Orthretum cancellatum & SI & 20.5 & 4 & 7.87 \\
\hline
\end{tabular}

SI Steinmann institute, Bonn, Germany 
license (GPL). Final tables and figures were edited with GIMP, Inkscape and Scribus (all GPL).

A three-dimensional model of the head of E. superstes is available [Electronic supplementary material 1 (ESM 1)], which facilitates the identification of internal structures. The underlying program 'Meshlab' can be downloaded free-ofcharge under the GPL license from http://meshlab.sourceforge.net/; any other VRML97 file viewer should work as well but was not tested by us. Please use the import function in Meshlab to open the file.

\section{Electron microscopy}

For scanning electron microscopy (SEM) the specimen was transferred in a series of steps into $100 \%$ ethanol, dried at the critical point (Model E4850, BioRad) and sputter-coated with gold (Model Anatech Hummer VII). Microscopy was performed on a Hitachi S-2460 N using a new type of rotatable sample holder (Pohl 2010). We consistently use the term 'suture' for ecdysial cleavage lines (DuPorte 1946, 1957; Snodgrass 1947) and 'ridge' for any cuticular strengthening lines or ridges (Snodgrass 1935, 1947; Strenger 1952), as was suggested by Wipfler et al. (2011). We avoid the term 'sulcus' completely as this normally refers to a fissure between bones. Muscles are named after the nomenclature introduced by Wipfler et al. (2011) stating the point of origin (O) and insertion (I) if a muscle is present. The descriptions of skeletal features follow Seifert (1995).

\section{Phylogenetic analyses}

Parsimony analyses of the morphological character set (see Appendix 1) and Bremer, as well as bootstrap, support calculations were carried out with TNT (Goloboff et al. 2008) using 1,000 heuristic searches starting with random addition of taxa (Tree-Bisection-Reconnection (TBR) branch swapping). All characters were equally weighted and unordered. Only unambiguous changes were mapped on the tree.

\section{Results}

\section{External head capsule}

The orthognathous head is strongly sclerotized and the surface is covered with a moderately dense vestiture of long setae (Fig. 1). It is of globular shape but slightly compressed in the anterior-posterior direction and dominated by the large, strongly convex, laterally placed compound eyes. They face almost completely forward as the occipital region covers the entire backside of the head (Fig. 1e). The eyes are enclosed by a complete, yet barely visible, circumoccular line which continues internally as a complete circumoccular ridge encircling the compound eyes. The dorsal parts of the eyes are pointed medially but do not touch each other. They are connected by an occipital bar. Directly anterad the occipital bar lies the occipital ridge. It proceeds posterad the lateral ocelli, touches the antennal ridge and is confluent with the dorsal tentorial pits located directly posterad the antennal base.

The lateral ocelli lie anterad the occipital ridge at level of the dorsal tips of the compound eyes. They are buried in the groove formed between the compound eyes and the grossly enlarged vertex protruding between the three ocelli. The vertex is formed like a shield oriented at a $45^{\circ}$ angle to the dorsoventral axis of the head (Fig. 1a, d). Its dorsal part is moderately indented by the moderate coronal suture (cs, Fig. 1b) which continues anterad over the edge of the vertex shield and splits after passing the edge into the frontal sutures (fs, Fig. 1a). The frontal sutures continue parallel to the dorsal vertex edge and obliterate at its lateral edges. Consequently, they do not reach the antennal bases.

The occipital region (oc, Fig. 1e) forms the major part of the backside of the head and bears the cephalic part of the arresting system, which is responsible for the support and fixation of the head in different situations (see Gorb 1999). The arresting system bears trichoid sensilla and sparsely distributed microtrichia. The part of the occipital region directly posterad the occipital bar bears numerous long, upwards directed setae (Fig. 1a).

The postocciput is small and divided into three parts: a halfmoon-shaped dorsal part and two lateral indented parts on both sides of the oval occipital foramen directly above the posterior tentorial pits. The postoccipital ridge encircles the postoccipital parts, but does not reach the posterior tentorial pits.

The large trapezoid clypeus is divided into an ante- and postclypeus, which are both heavily sclerotized (Fig. 1e). The anteclypeus is a third of the length of the postclypeus and encloses it on both sides. Both parts face anteriorly. A strong epistomal ridge (= transverse fronotclypeal strengthening line) separates the frons from the postclypeus. The frons is globular, protruding anteriorly and transversely elongated in frontal view. Together with the enlarged vertex it forms a groove with the middle ocellus at its base (moc, Fig. 1a). The anterior tentorial pits are continuous with the epistomal and pleurostomal ridges. The pleurostomal and hypostomal ridge (= subgenal ridge) are not continuous. The pleurostomal ridge is confluent with the circumocular ridge. The hypostomal ridge arises posterad from the posterior tentorial pits, passes the maxillar articulation and bends towards the posterior mandibular articulation with which it is confluent.

\section{Cephalic endoskeleton}

The anterior tentorial arms (ata, Fig. 2c) are short, massive and twisted. Wing-like protuberances emerge at their ventral base and extend into the lumen of the mandibles. They serve 


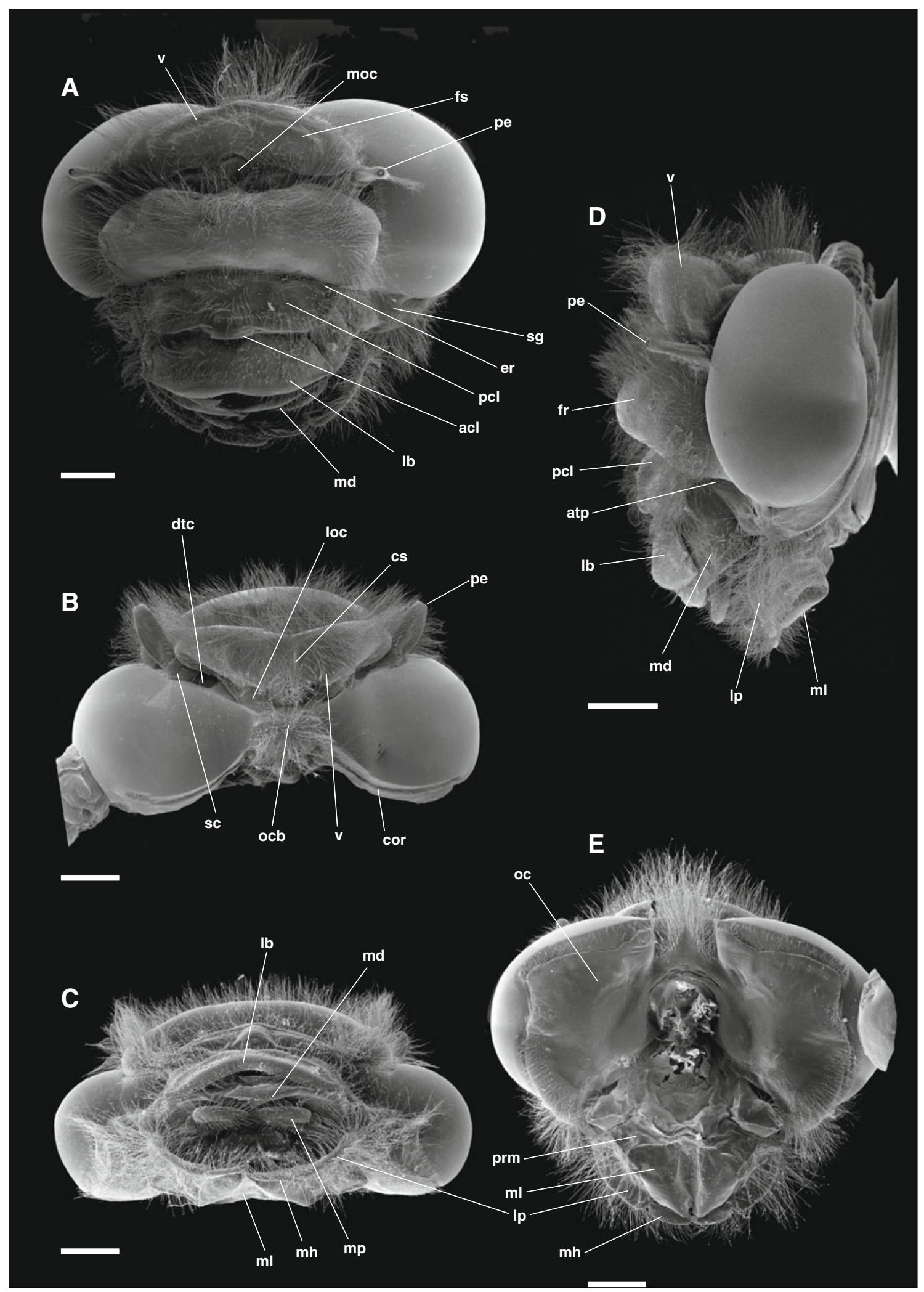

Fig. 1 Scanning electron micrographs of the head of Epiophlebia superstes $\mathbf{a}$, frontal view; b, dorsal view; c, ventral view; d, lateral view; e, posterior view. Abbreviations: acl anteclypeus, atp anterior tentorial pit, cor circumocular ridge, cs coronal sulcus, $d t c$ dorsal tentorial cavity, er epistomal ridge, $f r$ frons, $f_{s}$ frontal sulcus, $l b$ labrum, $l o c$ lateral ocellus, $l p$ labial palpus, $m d$ mandible, $m h$ moveable hook, $m l$ median lobe, $m o c$ median ocellus, $m p$ maxillary palpus, $o c$ occipital region, $o c b$ occipital bar, $p c l$ postclypeus, $p e$ pedicellus, prm prementum, $s c$ scapus, $s g$ subgena, $v$ vertex. Scale bars: $1 \mathrm{~mm}$ 


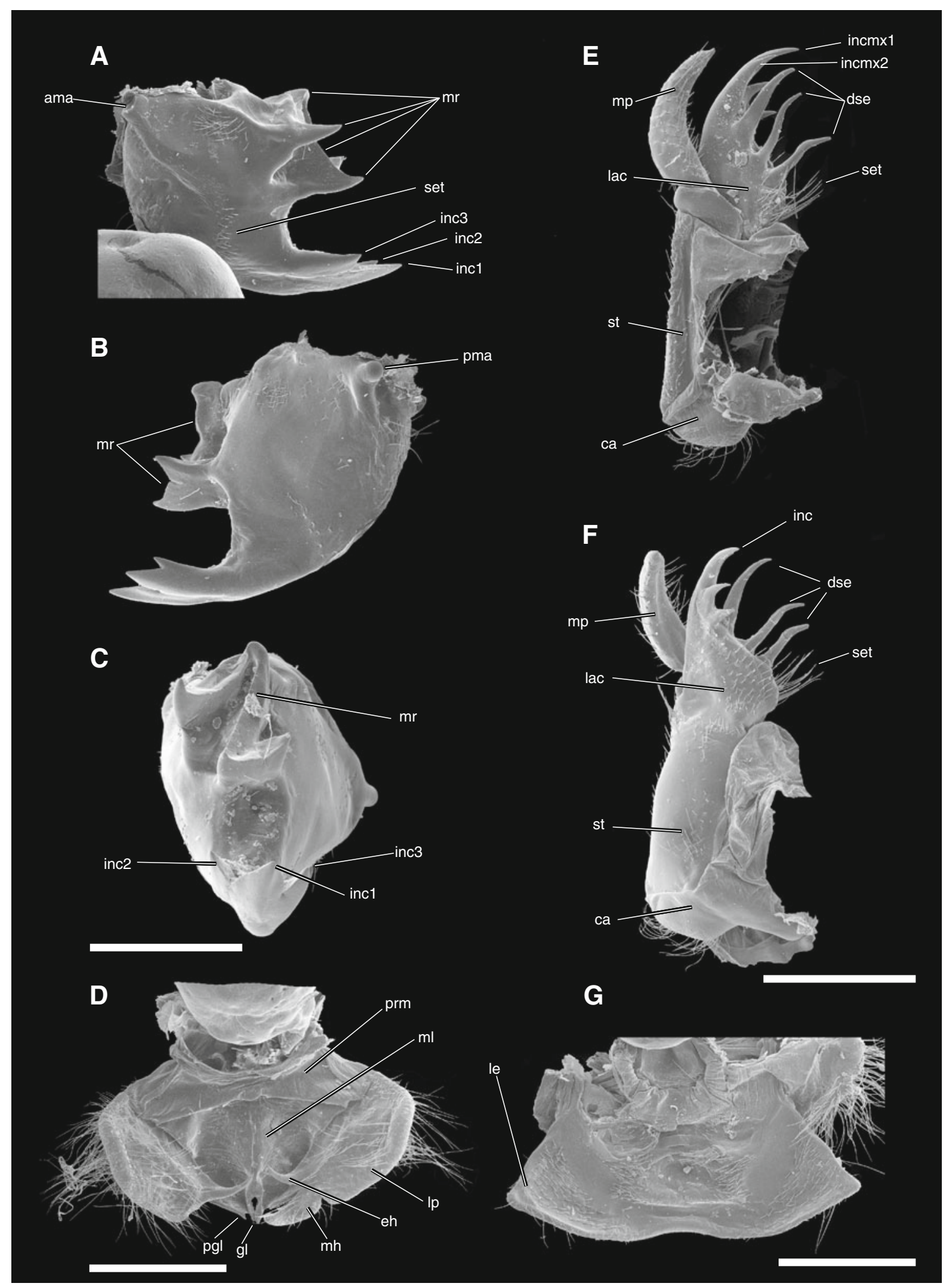

Fig. 2 Head muscle system of Epiophlebia superstes. a Frontal view with all labral and pharyngeal muscles; $\mathbf{b}$ the same muscles in lateral view. c Frontolateral view of the mandibular muscle system. d Frontal view of maxillar muscle system. e, f Frontal and lateral view of labial muscle system. Blue, chitinous structures (tentorium, mouthparts, ridges/ sutures); orange, muscles; green, digestive tract; red, eye. Abbreviations: ata anterior tentorial arm, $b r$ brain, $c a$ cardo; $c t$ corpotentorium, dent dentisetae, dta dorsal tentorial arm, eh end hook, hy hypopharynx, inc inscisivus, lac lacinia, $l b$ labrum, $l p$ labial palpus, $m d$ mandible, $m h$ moveable hook, $m l$ median lobe, $m p$ maxillar palpus, oc ocellus, ocr occipital suture, $p e$ pedicellus, $p h x$ pharynx, prm prementum, $s c$ scapus, $s t$ stipes, tor tormae. Scale bars: $1 \mathrm{~mm}$ 
as attachment sites for the mandibular muscles (0md6 and 0md8, Fig. 2c). The dorsal tentorial arms (dta, Fig. 2a) also originate from the base of the anterior arms. They are massive, not twisted and directly connected with the head capsule dorsad the antennal insertion. The attachment points are externally recognizable as dorsal tentorial cavities (dtp, Fig. 1b). All antennal muscles originate from the dorsal tentorial arms. The corpotentorium (= tentorial bridge; ct, Fig 2c) is compact and cylindrical. The posterior tentorial arms are very short and originate from the head capsule, directly dorso-proximad the articulation of the cardo. Short, but thick, apodemes - the trabeculae tentorii-originate from the ventral side of the posterior tentorial arms. They serve as attachment areas for the tentoriostipital muscles $0 \mathrm{mx} 4$ and $0 \mathrm{mx} 5$.

Musculature (Fig. 2; ESM 1): absent (0te1-0te6; see also ESM 2).

\section{Labrum}

The anteriorly-rounded, parabolic labrum almost completely covers the mandibles and is movably connected with the slightly convex anterior anteclypeal margin by a membranous fold. It bears a vestiture of setae (Fig. 1). The labrum is trapezoid in shape in frontal view and laterally strongly extended so that a spike is present on both sides. The labrum is ventrally wider than dorsally.

Musculature (Fig. 2; ESM 1): M. frontolabralis (0 lb1) broad, appearing unpaired over almost its entire length, but with paired subcomponents distinguishable posteriorly; O: mesally at the interantennal ridge; I: external wall of the labral base. M. frontoepipharyngalis $(0 \mathrm{lb} 2)-\mathrm{O}$ : laterad $0 \mathrm{lb} 1$ at the interantennal ridge; I: posterolateral edge of labrum, on short tormae. M. labroepipharyngalis (0 lb5) $\mathrm{O}$ : ventral of insertion point of $0 \mathrm{lb} 1$, median at the anterior labral wall; I: median at the dorsal part of the epipharyngeal wall. M. epistoepipharyngealis $(0 \mathrm{lb} 3)$, M. labralis transversalis (0 lb4), M. labrolabralis (0 lb6) - absent.

\section{Antenna}

The short antennae are composed of scapus, pedicellus and three flagellomeres. The antennal base strongly protrudes from the head capsule and is surrounded by a complete circumantennal ridge. Interantennal ridge, antennifer and antennal circulatory system are absent. The scapus is short, cylindrical and thick, and the pedicellus is three times as long. It is dorsoventrally flattened, but as thick as the scapus and densely covered with long hairs only along the lateral edges. The flagellomeres are thin: the first one is half as long as the pedicel; the second one is one third of the latter and the third one is half as long as the second.

Musculature (Fig. 2; ESM 1): M. tentorioscapalis anterior (0an1) - weakly developed; O: mesal wall of the dorsal tentorial arm just below the connection to the head; I: anteriorly on the scapal base. M. tentorioscapalis posterior (0an2) — weakly developed; O: directly dorsad 0an1; I: posteromesally on the scapal base. M. scapopedicellaris lateralis (0an6) - O: anterolaterally from the scapal base; I: anterolaterally on the base of the pedicellus; $\mathrm{M}$. scapopedicellaris medialis (0an7) - $\mathrm{O}$ : mesally from the scapal base; I: posteriorly on the base of the pedicellus; $\mathrm{M}$. tentorioscapalis lateralis (0an3), M. tentorioscapalis medialis (0an4), M. frontopedicellaris (0an5), M. intraflagellaris (0an8), M. interampullaris (0ah1), M. ampulloaortica (0ah2), M. ampullopharyngealis (0ah3), M. ampullofrontalis (0ah4), M. frontofrontalis (0ah5)-absent.

Mandibles

The articulation of the heavily sclerotized, slightly asymmetric mandibles is of the dicondylic (two articulations) ball-and-socket type (Fig. $3 \mathrm{a}+\mathrm{b}$ ). The mandible is triangular shaped in dorsal view. The anterior mandibular articulation (ama, Fig. 3a) is a socket while the posterior one (pma, Fig. 3b) is a distinct knob. The gnathal edges of the left and right mandibles are almost symmetrical. Each mandible bears three incisivi and a z-shaped mesal edge formed by four strongly sclerotized prominences connected by sharp ridges (mr, Fig. 3a, b, c). Additionally, the mandible bears several rows of setae on the anterior surface.

Musculature (Fig. 2; ESM 1): M. craniomandibularis internus $(0 \mathrm{md} 1)$, by far the largest muscle of the head - $\mathrm{O}$ : large parts of the posterodorsal and posterolateral areas of the head capsule; I: adductor tendon. M. craniomandibularis externus anterior $(0 \mathrm{md} 2)$ - absent. M. craniomandibularis externus posterior $(0 \mathrm{md} 3)-\mathrm{O}$ : laterally from the head capsule, composed of two major bundles, one originating below of $0 \mathrm{md} 1$ the other one more distally than $0 \mathrm{md} 1$; I: abductor tendon of the mandible. M. hypopharyngomandibularis $(0 \mathrm{md} 4)-\mathrm{O}$ : suspensorial bar of the hypopharynx; I: anterior inner wall of the mandible. M. tentoriomandibularis lateralis superior $(0 \mathrm{md} 5)-\mathrm{O}$ : posterior side of the anterior tentorial arm; I: posterior edge of the mandible between insertion of $0 \mathrm{md} 1$ and primary condyle. $M$. tentoriomandibularis lateralis inferior (0md6) - well developed, two parallel bundles - O: anterior tentorial arm with a tendon; I: anterior inner wall of the mandible ventrad of $0 \mathrm{md} 4$. M. tentoriomandibularis medialis superior $(0 \mathrm{md} 7)$-absent. M. tentoriomandibularis medialis inferior $(0 \mathrm{md} 8)-\mathrm{O}$ : anterior tentorial arm sharing the tendon with 0md6; I: posterior inner wall of the mandible.

\section{Maxillae}

The maxillae are long and slender. The undivided triangular cardo is clearly separated from the stipes by a small, barely recognizable cardostipital membrane. The stipes is a 

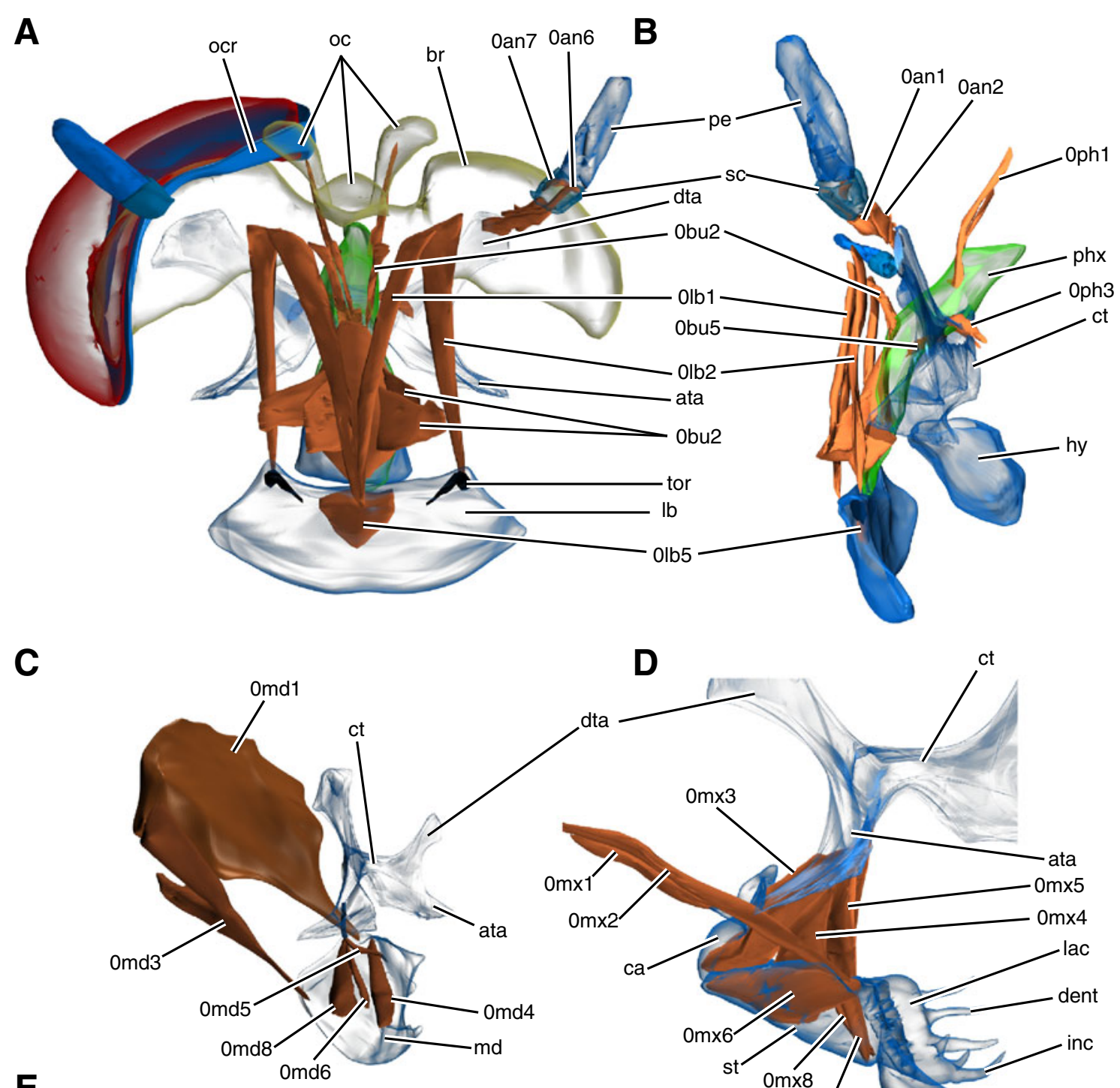

E
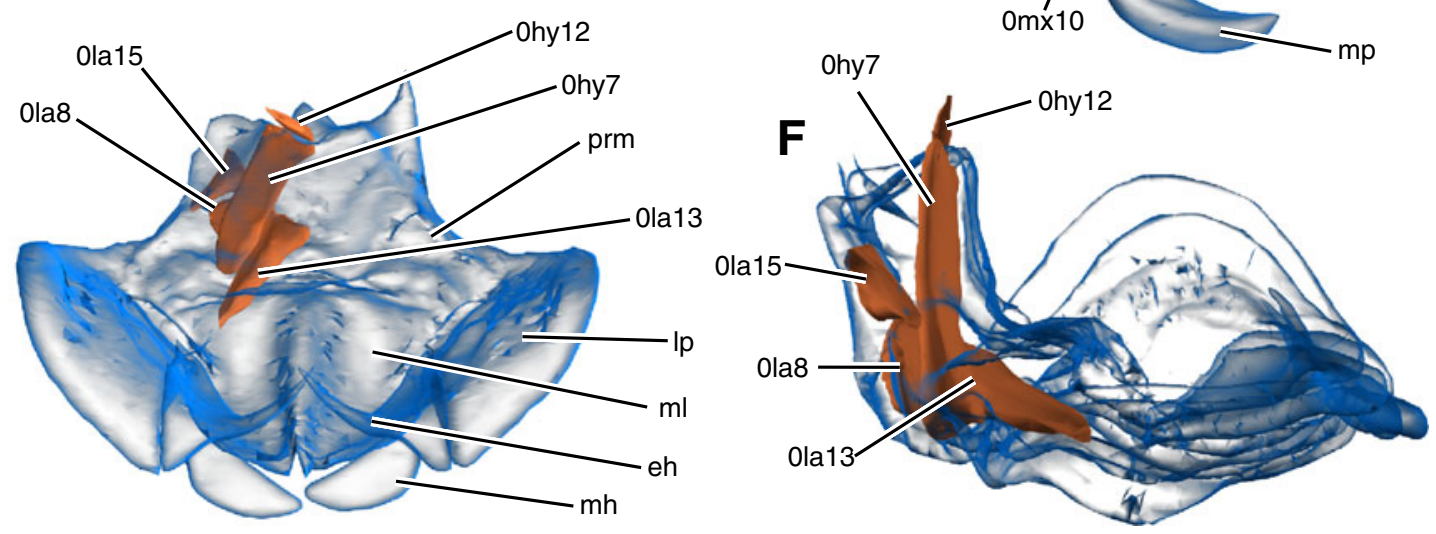

Fig. 3 Mouthparts of Epiophlebia superstes. Scanning electron micrographs. a Mandible frontal view. b Mandible posterior view. c Mandible lateral view. d Labium dorsal view. e Maxilla dorsal view. f Maxillae ventral view. $\mathbf{g}$ Labrum posterior view. Abbreviations: ama anterior mandibular articulation, $c a$ cardo, $d s e$ dentisetae, $e h$ end hook of labial palp, $g l$ glossa, incl first incisivus of mandible, inc 2 second incisivus of mandible, inc 3 third incisivus of mandible, incmxl first incisivus of maxilla, incm 2 second incisivus of maxilla, lac lacinia; le lateral extensions of labrum, $l p$ labial palp, $m h$ moveable hook of labial palp, $m l$ median lobe, $m p$ maxillary palp, $m r$ mesal ridge, $p m a$ posterior mandibular articulation, $\mathrm{pgl}$ paraglossa, prm prementum, set setae, st stipes. Scale bars: $1 \mathrm{~mm}$ 
rectangular plate subdivided by the stipital ridge into a narrow basistipes and a much larger mediostipes (Fig. 3e). Its distal part bears an unsegmented palpus covered with setae (mp, Fig. 3e, f). Mesally an oblique ridge separates the sickle-shaped lacinia from the stipes. Its mesal side is armed with a row of long setae, two apical incisivi and five subapical, strongly sclerotized dentisetae (dse, Fig. 3e, f). The galea is absent.

Musculature (Fig. 2; ESM 1): M. craniocardinalis $(0 \mathrm{mx} 1)$, fan-shaped-O: ventrolateral area of the head capsule between $0 \mathrm{md} 1$ and $0 \mathrm{md} 3$; I: basal process of the cardo with a tendon. M. craniolacinialis ( $0 \mathrm{~m} \times 2)$, a long and slender muscle with two bundles - $\mathrm{O}$ : head capsule, dorsally to $0 \mathrm{mx} 1$; I: basal edge of lacinia. M. tentoriocardinalis ( $0 \mathrm{mx} 3)$, $\mathrm{O}$ : ventrolaterally on the corpotentorium; I: inner surface of the cardo; M. tentoriostipitalis anterior $(0 \mathrm{mx} 4)-\mathrm{O}$ : along the entire ventral side of the corpotentorium and the tentorial ridge, anterad to $0 \mathrm{mx} 2$; I: broadly on the ventral stipital wall; $\mathrm{M}$. tentoriostipitalis posterior $(0 \mathrm{~m} \times 5)-\mathrm{O}$ : ventrolateral side of the corpotentorium, anterior to $\mathrm{M}$. tentoriocardinalis $(0 \mathrm{mx} 3)$; I: basal outer stipital wall, close to the stipitocardinal ridge. M. stipitolacinialis $(0 \mathrm{mx} 6)$, welldeveloped, fan-shaped - $\mathrm{O}$ : ventrolateral surface of the stipital base; I: proximal base of lacinia. M. stipitopalpalis externus $(0 \mathrm{mx} 8)-\mathrm{O}$ : lateral inner wall of the stipital ridge; I: posteriorly on the base of the palpus. M. stipitopalpalis internus (0mx10) - well developed; O: lateral inner wall of the stipital ridge; I: anteriorly on the base of the palpus. M. stipitogalealis $(0 \mathrm{~m} \times 7)$, M. stipitopalpalis medialis $(0 \mathrm{mx} 9)$, M. stipitalis transversalis ( $0 \mathrm{mx} 11)$, M. palpopalpalis maxillae primus $(0 \mathrm{mx} 12)$, M. palpopalpalis maxillae secundus (0mx13), M. palpopalpalis maxillae tertius (0mx14), Musculus palpopalpalis maxillae quartus $(0 \mathrm{mx} 15)$-absent.

\section{Labium}

The labium consists of a basal postmentum and a distal prementum (prm, Figs. 1e and $3 \mathrm{~d}$ ). The postmentum is a rectangular plate and reinforced by heavily sclerotized bars dorsally, ventrally and laterally. The short and broad prementum forms a right angle with the postmentum, which is visible in lateral view. Apically, it bears paired one-segmented palps and paired median lobes. The palps are flat and densely covered with setae, particularly on the outer side. Apicomesally, they bear a fixed subapical hook (eh). A second movable hook (mh) is present distad of this hook (Fig. 3d). The median lobes are a fusion product of the proximal parts of glossae and paraglossae. Mesally, the two lobes are connected by a sclerotized stripe which is as long as the lobes themselves. Only the tips of the glossae and paraglossae are visible (Fig. 3d). The palps and median lobes together form a cavity for reception of the hypopharynx and maxillae.
Musculature (Fig. 2; ESM 1): M. submentopraementalis (0la8) - O: medially on the posterior submentum, I: dorsally on the inner wall of the premental base. M. praementopalpalis internus (0la13) - $\mathrm{O}$ : medially on the prementum; I: mesally on the anterior base of the palpus. M. praementomembranus (01a15) - O: medially on the prementum; I: dorsal membrane of prementum. M. postoccipitoglossalis medialis (0la1), M. postoccipitoglossalis lateralis (0la2), M. postoccipitoparaglossalis (0la3), M. postoccipitoprementalis (0la4), M. tentoriopraementalis (0la5), M. tentorioparaglossalis (0la6), M. tentorioglandularis (0la7), M. postmentomembranus (0la9), M. submentomentalis (0la10), M. praementoparaglossalis (0la11), M. praementoglossalis (01a12), M. praementopalpalis externus (0la14), M. palpopalpalis labii primus (0la16), M. palpopalpalis labii secundus (0la17) —absent.

\section{Hypopharynx and suspensorium}

The hypopharynx is a ventrally-oriented, tongue-like structure in front of the prementum. It is weakly sclerotized and bears no anterior or posterior plates. A conspicuous row of hairs is present on the lateral surfaces. The suspensorium is heavily sclerotized and formed like a bracelet. The oral arm forms a rounded bar directly posterad the anatomical mouth opening. Its serves as attachment site for M. oralis transversalis (0hy9). The loral arm is thin.

Musculature (Fig. 2; OR 1): M. praementosalivaris anterior (0hy7) - O: anterolateral prementum; I: ventrally on the sclerotized floor of the anteriormost salivary duct. M. oralis transversalis (0hy9) - $\mathrm{O}$ : oral arm of suspensorial sclerite; I: oral arms of suspensorial sclerite on the opposite side. $\mathrm{M}$. loroloralis (0hy10) - absent. M. hypopharyngosalivaris (0hy12) - O: hypopharyngeal suspensorium; I: suprasalivarial sclerite, close to the salivarial orifice. $\mathrm{M}$. frontooralis (0hy1), M. tentoriooralis (0hy2), M. craniohypopharyngealis (0hy3), M. postoccipitalohypopharyngealis (0hy4), M. tentoriosuspensorialis (0hy5), M. postmentoloralis (0hy6), M. praementosalivaris posterior (0hy8), M. lorosalivarialis (0hy11), M. annularis salivarii (0hy13)—absent.

\section{Epipharynx}

The epipharynx is weakly sclerotized and not subdivided. It bears a single lateral row of setae on both sides. The tormae are formed like an inverted ' $\mathrm{Y}$ ' in posterior view. They serve as attachment areas of M. frontoepipharyngalis (0lb2).

Salivarium and salivary glands

The salivary glands are paired, mesally connected, globular structures. They are located directly ventrad the deutocerebrum and dorsad the salivary receptacle. The paired salivary 
ducts fuse before opening into the salivary receptacle, which is anteriorly continuous with an unpaired salivary channel. The channel opens into the salivarium posterad the hypopharynx at about a third of its total length.

Pharynx and oesophagus

The pharynx and oesophagus have a wide lumen. Several dorsal, lateral and ventral folds serve for muscle attachment.

Musculature (Fig. 2; ESM 1): M. clypeobuccalis (0bu1) present. M. frontobuccalis anterior (0bu2) - $\mathrm{O}$ : interantennal ridge posterior to the $0 \mathrm{lb} 1$; I: dorsal buccal wall, posterior to the ganglion frontale. M. tentoriobuccalis anterior (0bu5) - one bundle; O: anterior wall of corpotentorium; I: ventral buccal wall. M. verticopharyngealis ( 0 ph1) - $\mathrm{O}$ : posterior head capsule, posterad the brain, mediad of $0 \mathrm{md} 1$; I: dorsal pharyngeal wall. M. postoccipitopharyngealis $(0 \mathrm{ph} 3)-\mathrm{O}$ : head capsule close to the posterior tentorial pit; I: ventral pharyngeal wall, below the attachment of M. verticopharyngalis ( $0 \mathrm{ph} 1)$. M. clypeopalatalis (0ci1), M. frontobuccalis posterior (0bu3), M. tentoriobuccalis lateralis (0bu4), M. tentoriobuccalis posterior (0bu6), M. tentoriopharyngealis $(0 \mathrm{ph} 2)$-absent.

\section{Phylogenetic analysis of head characters}

The analysis of the head character matrix (see appendix) yielded one most parsimonious tree supporting a sistergroup relationship of Anisozygoptera + Anisoptera (= Epiprocta fide Lohmann (1996) Fig. 4). Epiprocta are supported by the following synapomorphies: loss of M. tentoriomandibularis medialis superior $(0 \mathrm{md} 7$; 10), eyes separated by less than their own width (11), anteclypeus and postclypeus facing anteriorly (12) and a vertex formed as a protuberance (14).

Anisoptera are supported by the presence of an epistomal and interantennal ridge $(17+18)$ which is absent in Epiophlebiidae, Zygoptera and Ephemeroptera. Anisozygoptera are supported by the unique shape of labium (13) and pedicellus (15).

\section{Discussion}

The morphology of E. superstes, the Japanese species of Epiophlebiidae, was already investigated more than six decades ago (Asahina 1954). However, the account of internal structures remained fragmentary. This is also true for the rest of Odonata, especially Zygoptera (Mathur and Mathur 1961; Short 1955).

Our study revealed three additional mandible muscles (0md4 'M. hypopharyngo mandibularis', 0md6 'M. zygomaticus mandibulae anterior', $0 \mathrm{md} 8$ 'M. zygomaticus mandibulae posterior'), which are also consistently found in Zygoptera and Anisoptera (see ESM 2). M. tentoriomandibularis medialis superior $(0 \mathrm{md} 7)$ is absent in adults of E. superstes. It is also missing in Calopterygidae, Neopetaliidae, Aeshnidae [see also Short (1955)], Libelullidae, Macromiidae and Corduliidae, but is present in Lestidae, Coenagrionidae, Platycnemididae, Austropetaliidae, Cordulegastridae, Petaluridae and Gomphidae. This muscle belongs to the groundplan of Ephemeroptera and Zygentoma (Staniczek 2000, 2001) and apparently also of Odonata. The loss apparently occurred several times independently inside Odonata. Based on the available data we postulate the primary absence of $0 \mathrm{md} 7 \mathrm{in}$ Anisoptera (Fig. 4).

The composition of M. craniomandibularis externus $(0 \mathrm{md} 3)$ in E. superstes is unusual. The abductor comprises one major muscle package and a smaller one with different origin. The smaller part originates below M.craniomandibularis internus (0md1), the larger part more distad to it. Both packages insert at the abductor tendon of the mandible. The studied calopterygid shows a similar condition of this muscle. This arrangement is similar to the condition found in Ephemeroptera (Staniczek 2001) for 0md2 and 0md3. In contrast to Odonata, these two muscles are discernible as separate bundles from origin to insertion in Ephemeroptera, although they have the same function and their insertion points are almost adjacent (Staniczek 2000, 2001). Owing to the peculiar structure of $0 \mathrm{md} 3$ in Odonata, we assume a fusion of $0 \mathrm{md} 2$ and $0 \mathrm{md} 3$ based on our data (see Figs 2 and 4). The antennal musculature is typical for Odonata, with two tentorio-scapal muscles inserting at the scapus. Two scapo-pedicellar muscles move the pedicellus. The available

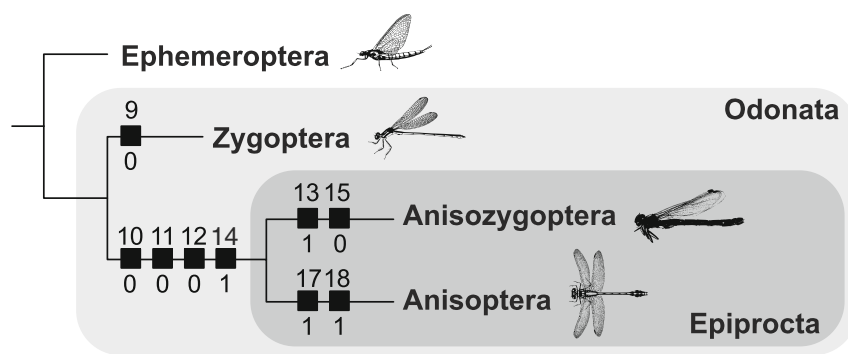

Fig. 4 Phylogram summarizing the characters of the head supporting a sistergroup relationship of Epiophlebiidae with the rest of Anisoptera 
data suggests that antennal circulatory systems are absent in adults of $E$. superstes and other adult odonatans, whereas they were reported by Pass (1991) for some odonatan larvae.

In contrast to Asahina's (1954) drawings, bucca and pharynx of E.superstes are equipped with more muscles. Our study revealed a second $\mathrm{M}$. frontobuccalis originating very close to the $\mathrm{M}$. frontobuccalis anterior medially on the interantennal ridge. More posteriorly the pharynx is dorsally connected with the head by the $M$. verticopharyngalis (0ph1).

The ventral dilators of the bucca and pharynx are $M$. tentoriobuccalis anterior (0bu5) and M. postoccipitopharyngalis (0ph3). The muscular equipment of the bucca and pharynx is the same as in all other studied odonatans. It is a reduced type compared with the condition in Ephemeroptera (see ESM 2).

The majority of studies recover Ephiophlebiidae as a sister taxon to extant Anisoptera (= Epiprocta). Matushkina (2008) found that the morphology of the ovipositor and the egglaying behaviour of $E$. superstes bears several similarities with zygopterans. In contrast, Dumont et al. (2010) recovered Epiophlebiidae as a sister taxon to Cordulegastridae.

The head muscle equipment of E. superstes shows a similar composition compared with Lestidae and Gomphidae (Figs 2 and 4, Table ESM 2). Possible anatomical groundplan features of Odonata are the fusion of M. craniomandibularis externus anterior (0md2) and M. craniomandibularis externus $(0 \mathrm{md} 3)$, and the absence of $\mathrm{M}$. tentoriopraementalis inferior (0la5) and $\mathrm{M}$. praementoparaglossalis (0la11). The two labial muscles are present in all studied Zygentoma, Ephemeroptera and Neoptera studied (Blanke et al. 2012 in press). Although the head muscle equipment of $E$. superstes allows no final conclusion as to its phylogenetic position, other head structures point towards a sistergroup relationship with Anisoptera (Fig. 4). However, we agree only in part with the number of cephalic synapomorphies proposed for Epiprocta previously (Asahina 1954: 121). Asahina (1954) stated that the position of the antennal foramen, which is situated dorsolaterally to the head capsule and the swollen frontal parts of the head (clypeus and vertex), are typical anisopteric features. In our view, the enlargement of the vertex shifts the position of the antennal foramen towards a dorsolateral position. Also, the enlargement and globular shape of the compound eyes in Epiprocta restricts the size of the dorsal portion of the occiput. In contrast, Asahina (1954) proposed the shape of occiput and eyes as separate characters. It is apparent that the position of the antennae and the structure of the frontal parts, as well as the configuration of the eyes and occiput, are interconnected characters in the cephalic construction of Epiprocta. Considering all these characters as independent synapomorphies in phylogenetic analyses would be equivalent with artificially increased weight.
Dumont et al. (2010) recovered Epiophlebia as a sister to Cordulegastridae based on $18 \mathrm{~S}, 5.8 \mathrm{~S}$ and ITS1 and 2 sequences. Although the deep relationships among Anisoptera are still not solved, other molecular studies consistently retrieve Anisozygoptera as sister to Anisoptera (Bybee et al. 2008; Fleck et al. 2008; Letsch et al. 2009; Misof et al. 2001). Morphologically, a sistergroup relationship of Epiophlebiidae with Cordulegastridae is equally unlikely. This would imply secondary changes in several wing characters: the form of the costal basivenale $(\mathrm{BxC}$; an articular wing sclerite at the base of costa and subcosta distal to the anterior platform), the origin of the MP vein, the presence of a membranule and the shape of the costa at the nodus, as well as the shape of the vesica spermalis inside Anisoptera (Asahina 1954). Head characters also support a position of Epiophlebiidae as sister to all Anisoptera (Fig. 4).

Likewise, we cannot follow the argumentation for a closer relationship of Epiophlebiidae with Zygoptera (Matushkina 2008). Although Epiophlebia shares the muscle set and muscle branching pattern inside the ovipositor with Calopteryx (Matushkina 2008), Klass (2008) judged the evidence for a relationship Epiophlebia + Zygoptera not very strong based on his investigations of the exoskeleton and musculature of ovipositor bearing Odonata. According to this study the abdominal characters presently available provide no resolution for the relationships between Zygoptera, Anisozygoptera and Anisoptera.

Our study shows that despite detailed anatomical studies (Asahina 1954) performed decades ago, our knowledge about odonate head morphology is still fragmentary. Reanalyses are certainly worth the effort as errors are corrected and important new answers to phylogenetic questions are given (Blanke et al. 2012; Wipfler et al. 2011). The detailed knowledge of the head morphology of E. superstes is apparently crucial for the reconstruction of the groundplan of Odonata. In particular, Odonata and Ephemeroptera are interesting subjects because of their essential role in answering the evolution of flight in insects and their phylogenetic relation to Neoptera, which has not yet been resolved. Head characters provide phylogenetic signals for a sistergroup relationship of Anisozygoptera and Anisoptera, formal analyses of a broad spectrum of characters, including extensive datasets from the thorax, abdomen and the genitalic region, are not yet possible because of homologisation problems.

Acknowledgment Fabian Wilde (HZG, Geesthacht), as well as Sebastian Thieß and Wolfgang Drube (DESY, Hamburg), provided excellent support at the DESY synchrotron facilities. The scanning was done in the course of proposals no. I-20080169 and I-20090211. Marco Stampanoni and Peter Modregger are sincerely thanked for their support at the PSI for SLS TOMCAT beamline analysis (proposals 20100137 and 20110069). Irina Ruf (Steinmann Institute, Bonn, Germany) made microCT investigations at the device of the Steinmann Institute possible. We would like to express our gratitude to Professor Ryuichiro Machida (University of Tsukuba, Japan) who kindly 
provided specimens of E. superstes. Benjamin Wipfler and Rolf Beutel (University of Jena, Germany) are thanked for useful advice. Furthermore, we thank two anonymous reviewers for their valuable comments. The laboratory members of the ZFMK are sincerely thanked for their support.

\section{Appendix 1. Character discussion (Fig. 4; ESM 3)}

0. Composition of mandibular abductor: (0) undivided $(0 \mathrm{md} 3)$; (1) divided into two bundles $(0 \mathrm{md} 2$ and 0md3). Ephemeroptera possess two mandibular abuctors $(0 \mathrm{md} 2$ and $0 \mathrm{md} 3)$. In Odonata only the $0 \mathrm{md} 3$ is present. The muscle is divided distally into two bundles. The origin of the two bundles closely resembles the origin of $0 \mathrm{md} 2$ and $0 \mathrm{md} 3$ in Ephemeroptera.

1. M. frontobuccalis lateralis: (0) absent; (1) present. In Odonata M. frontobuccalis lateralis (0hy2), M. tentoriohypopharyngalis (0hy3) and M. praementosalivarialis posterior (0hy8) are absent. Ephemeroptera possess these muscles (Staniczek 2000, 2001).

2. M. tentoriohypopharyngalis (0hy3): (0) absent; (1) present.

3. M. praementosalivarialis posterior (0hy8): (0) absent; (1) present.

4. M. tentoriopraementalis inferior (0la5): (0) absent; (1) present. The labial muscles $\mathrm{M}$. tentoriopraementalis inferior (0la5) and M. praementoglossalis (0la11) are absent in Odonata, but present in Ephemeroptera.

5. M. praementoglossalis (0la11): (0) absent; (1) present.

6. Galea: (0) absent; (1) present. Ando (1962) discovered that no galea is formed during embryonic development in Odonata. In Ephemeroptera the galea is fused with the lacinia but still discernible in certain taxa (Staniczek 2000, 2001).

7. Salivary system: (0) absent; (1) present. A salivary system is present in Odonata but absent in Ephemeroptera.

8. Head: (0) transversely elongate; (1) globular. The head of Zygoptera is transversely elongated with the domeshaped eyes located at the distal ends.

9. M. tentoriomandibularis medialis superior ( $0 \mathrm{md} 7)$ : $(0)$ absent; (1) present. The M. tentoriomandibularis medialis superior $(0 \mathrm{md} 7)$ is present in all studied Zygoptera and Ephemeroptera. It is also present in the anisopteran taxa Austropetaliidae, Cordulegastridae, Petaluridae and Gomphidae but absent in Neopetaliidae, Aeshnidae, Libelullidae, Macromiidae and Corduliidae. Owing to its absence in E. superstes the primary loss of $0 \mathrm{md} 7$ is regarded as a groundplan feature of Epiprocta.

10. Eyes: (0) seperated by less than their own width; (1) separated by more than their own width. In all adult Anisoptera and Anisozygoptera the eyes are separated by less than their own width, all Zygoptera and Ephemeroptera show the opposite state.

11. Anteclypeus and postclypeus: (0) not facing anteriorly; (1) facing anteriorly. In Zygoptera the anteclypeus and postclypeus can form distinct anterior and dorsal faces respectively. It can also be greatly swollen (e.g., Chlorocyphidae). Anteclypeus and postclypeus face anteriorly in all studied Anisoptera. In contrast to Rehn (2003) this state is also present in E. superstes.

12. Labrum transversely enlarged: (0) absent; (1) present. The lateral sides of the labrum are strongly protruding transversely in E. superstes. This is a potential autapomorphy of Epiophlebiidae.

13. Vertex: (0) flat; (1) grossly enlarged and shield like; (2) formed as a moderate protuberance. A flat vertex characterizes all Zygoptera. All Anisoptera and Anisozygoptera exhibit a more or less prominent elevation of the vertex. The unique shape of the vertex in E. superstes is a potential autapomorphy of Anisozygoptera.

14. Pedicellus: (0) flattened with a lateral vestiture of long setae; (1) not as above. The shape and structure of the pedicellus is another potential autapomorphy of Epiophlebiidae.

15. M. frontobuccalis posterior (0bu3): (0) absent; (1) present. The 0 bu 3 is present in E. superstes but absent in all Anisoptera and Zygoptera. It is also present in Ephemeroptera.

16. Internal part of the interantennal ridge (interantennal apodeme): (0) absent; (1) present. An interantennal apodeme originating at the interantennal ridge is present in all studied Anisoptera and absent in E. superstes and Zygoptera.

17. Internal part of the epistomal ridge (epistomal apodeme): (0) absent; (1) present. An epistomal apodeme originating at the epistomal ridge is present in all studied Anisoptera and absent in E. superstes and Zygoptera.

\section{References}

Ando, H. (1962). The comparative embryology of Odonata with special reference to a relic dragonfly. Epiophlebia superstes. Tokyo: The Japan Society for the Promotion of Science.

Asahina, S. (1954). A morphological study of a relic dragonfly Epiophlebia superstes Selys (Odonata, Anisozygoptera). Tokyo: The Japan Society for the Promotion of Science.

Bechly, G. (1996). Morphologische Untersuchungen am Flügelgeäder der rezenten Libellen und deren Stammgruppenvertreter (Insecta; Pterygota; Odonata) unter besonderer Berücksichtigung der phylogenetischen Systematik und des Grundplanes der Odonata. Petalura, 2, 1-402.

Beckmann, F., Herzen, J., Haibel, A., Müller, B., \& Schreyer, A. (2008). High density resolution in synchrotron-radiation-based 
attenuation-contrast microtomography. Proceedings of SPIE, 7078, 70781D-70783D

Betz, O., Wegst, U., Weide, D., Heethoff, M., Helfen, L., Lee, W.-K., et al. (2007). Imaging applications of synchrotron X-ray phasecontrast microtomography in biological morphology and biomaterials science. I. General aspects of the technique and its advantages in the analysis of millimetre-sized arthropod structure. Journal of Microscopy, 227, 51-71.

Blanke, A., Wipfler, B., Letsch, H., Koch, M., Beckmann, F., Beutel, R. G., \& Misof, B. (2012). Revival of Palaeoptera - head characters support a monophyletic origin of Odonata and Ephemeroptera (Insecta). Cladistics (in press).

Bybee, S. M., Ogden, T. H., Branham, M. A., \& Whiting, M. F. (2008). Molecules, morphology and fossils: a comprehensive approach to odonate phylogeny and the evolution of the odonate wing. Cladistics, 23, 1-38.

Carle, F. L. (1982). The wing vein homologies and phylogeny of the Odonata: a continuing debate. Societas Internationalis Odonatologica Rapid Communications, 4, 1-66.

Dumont, H. J., Vierstraete, A., \& Vanfleteren, J. R. (2010). A molecular phylogeny of the Odonata (Insecta). Systematic Entomology, $35,6-18$

DuPorte, E. M. (1946). Observations on the morphology of the face in insects. Journal of Morphology, 79, 371-417.

DuPorte, E. M. (1957). The comparative morphology of the insect head. Annual Review of Entomology, 2, 55-70.

Fiala, J. C. (2005). Reconstruct: a free editor for serial section microscopy. Journal of Microscopy, 218, 52-61.

Fleck, G., Ullrich, B., Brenk, M., Wallnisch, C., Orland, M., Bleidissel, S., et al. (2008). A phylogeny of anisopterous dragonflies (Insecta, Odonata) using mtRNA genes and mixed nucleotide/ doublet models. Journal of Zoological Systematics and Evolutionary Research, 46, 310-322.

Gade, G., Simek, P., \& Fescemyer, H. W. (2011). Adipokinetic hormones provide inference for the phylogeny of Odonata. Journal of Insect Physiology, 57, 174-178.

Goloboff, P. A., Farris, J. S., \& Nixon, K. C. (2008). TNT, a free program for phylogenetic analysis. Cladistics, 24, 774-786.

Gorb, S. N. (1999). Evolution of the dragonfly head-arresting system. Proceedings of the Royal Society of London. Series B: Biological Sciences 266, 525-535.

Klass, K.-D. (2008). The female abdomen of ovipositor-bearing Odonata (Insecta: Pterygota). Arthropod Systematics \& Phylogeny 66, 45-142.

Letsch, H. O., Greve, C., Kück, P., Fleck, G., Stocsits, R. R., \& Misof, B. (2009). Simultaneous alignment and folding of 28 S rRNA sequences uncovers phylogenetic signal in structure variation. Molecular Phylogenetics and Evolution, 53, 758-771.

Li, J.-K., Nel, A., Zhang, X.-P., Fleck, G., Gao, M.-X., Lin, L. I. N., et al. (2012). A third species of the relict family Epiophlebiidae discovered in China (Odonata: Epiproctophora). Systematic Entomology, 37, 408-412.
Lohmann, H. (1996). Das phylogenetische System der Anisoptera (Odonata). Entomologische Zeitschrift, 106, 209-266.

Mathur, P. N., \& Mathur, K. C. (1961). Studies on the cephalic musculature of adult Ictinus angulosus Selys (Odonata, Anisoptera, Gomphidae, Ictinae). Journal of Morphology, 109, 237-249.

Matushkina, N. A. (2008). The ovipositor of the relic dragonfly Epiophlebia superstes: a morphological re-examination (Odonata: Epiophlebiidae). International Journal of Odonatology, 11, 71-80.

Misof, B., Rickert, A. M., Buckley, T. R., Fleck, G., \& Sauer, K. P. (2001). Phylogenetic signal and its decay in mitochondrial SSU and LSU rRNA gene fragments of Anisoptera. Molecular Biology and Evolution, 18, 27-37.

Pass, G. (1991). Antennal circulatory organs in Onychophora, Myriapoda and Hexapoda - Functional morphology and evolutionary implications. Zoomorphology, 110, 145-164.

Pohl, H. (2010). A scanning electron microscopy specimen holder for viewing different angles of a single specimen. Microscopy Research and Technique, 73, 1073-1076.

Rehn, A. C. (2003). Phylogenetic analysis of higher-level relationships of Odonata. Systematic Entomology, 28, 181-239.

Romeis, B. (1989). Mikroskopische Technik (17). Munich: Urban \& Schwarzenberg.

Seifert, G. (1995). Entomologisches Praktikum (3rd ed.). Stuttgart: Georg Thieme Verlag.

Short, J. R. T. (1955). The morphology of the head of Aeshna cyanea (Müller) (Odonata, Anisoptera). Transactions of the Royal Entomological Society London, 106, 197-211.

Snodgrass, R. E. (1935). Principles of insect morphology. McGrawHill, New York, XXX.

Snodgrass, R. E. (1947). The insect cranium and the "epicranial suture". Smithsonian Miscellaneous Collections, 107, 1-52.

Staniczek, A. H. (2000). The mandible of silverfish (Insecta: Zygentoma) and mayflies (Ephemeroptera): Its morphology and phylogenetic significance. Zoologischer Anzeiger, 239, 147-178.

Staniczek, A. H. (2001). Der Larvenkopf von Oniscigaster wakefieldi McLachlan, 1873 (Insecta: Ephemeroptera: Oniscigastridae). Ein Beitrag zur vergleichenden Anatomie und Phylogenie der Eintagsfliegen. PhD thesis, Eberhard-KarlsUniversität Tübingen.

Strenger, A. (1952). Die funktionelle und morphologische Bedeutung der Nähte am Insektenkopf. Zoologische Jahrbücher, 72, $468-521$.

Tillyard, R. J. (1921). On an anisozygopterous larva from the Himalayas (Order Odonata). Records of the Indian Museum, 22, 93 107.

Trueman, J. W. H. (1996). A prelimnary cladistic analysis of odonate wing venation. Odonatologica, 25, 59-72.

Wipfler, B., Machida, R., Müller, B., \& Beutel, R. G. (2011). On the head morphology of Grylloblattodea (Insecta) and the systematic position of the order, with a new nomenclature for the head muscles of Dicondylia. Systematic Entomology, 36, 241-266. 